\title{
A SOCIOLOGIA CULTURAL E SEU ENSINO
}

\author{
Claude Lévi-Strauss*
}

[175]

Os sociólogos se encontram ainda no estágio em que há mais preocupação de se saber o que seja sociologia do que de estudar a sociedade. A superabundância dos estudos dos fatos e seu pouco alcance condenam as concepções universitárias. A bem dizer, é surpreendente reconhecer que, depois de um século de reflexões ininterruptas sobre os fenômenos sociais, não possuímos ainda um tratado sistemático de sociologia do gênero dos proporcionados por Wundt e William James na alvorada da psicologia.

Aqueles que atribuem tal fato a um erro metodológico ${ }^{1}$ são responsáveis pelo mesmo abuso que acabo de assinalar. Disso devemos simplesmente concluir que, do ponto de vista dos resultados, bem como dos métodos, a Sociologia não atingiu ainda o estágio em que se encontrava a psicologia aproximadamente em 1880.

As obras gerais, em sua grande maioria, concebem a sociologia como uma espécie de método universal que permite abordar todos os problemas defrontados, sob qualquer título, pelo homem. A sociologia jurídica encara as questões de direito; a sociologia econômica, a da economia política; a sociologia religiosa concerne à história das religiões, etc. Oferece-se, pois, não uma síntese, mas uma visão sintética insípida do conjunto dos estudos sociais, como se um único indivíduo, desde que se intitule sociólogo, fosse capaz de resolver uma quantidade prodigiosa de problemas, dos quais cada [176] um requer, para seu estudo particular, um número respeitável de especialistas.

O perigo dessa concepção usual é duplo: de um lado, a sociologia se apresenta no plano de uma "filosofia das ciências sociais", pois, na impossibilidade de

Publicação original: LÉvi-STrauss, C. A sociologia cultural e o seu ensino. Anuário da Faculdade de Filosofia, Ciências e Letras 1934-1935, edição fac-símile, p. 175-184, [1937] 2009.

1 ZnANIECKI, F. The object matter of sociology. The American Journal of Sociology, I-XXXII, jan. 1927. 
submeter os problemas a um tratamento real, o tratamento especulativo continua a se apresentar como um refúgio de "tout repos".

Em seguida, ela orienta a sociologia para preocupações práticas e normativas. Ora, se entendermos por ciência um esforço de sistematização racional que se exerce sobre certa classe de dados empíricos, é evidente que uma disciplina, preocupada com aplicações práticas, não poderia ser uma ciência. Toda atividade prática utiliza dados de várias ciências. A construção de uma ponte tanto exige conhecimentos físicos quanto matemáticos, geológicos ou botânicos. A arte social - caso exista - não se apoia menos sobre a biologia e a psicologia do que sobre a sociologia propriamente dita. E não pertence mais a esta última mais do que, em relação à física, a arte do engenheiro que dela é um ramo ou uma aplicação.

Um esforço de definição arbitrária não basta para dar nascimento a uma ciência nova. A sociologia não nascerá de especulações metodológicas, mas da extensão espontânea dos resultados cientificamente válidos que o estudo das coletividades humanas tem fornecido até hoje. São os da arqueologia e da etnologia: uma entendendo-se com as sociedades como já desaparecidas, a outra com as sociedades como primitivas. Uma e outra, tal como a própria sociologia, realizando um estudo de cultura, isto é, dos modos de vida das coletividades humanas. Entendemos, com efeito, por cultura: a) um conjunto dado de gêneros de vida; b) distribuídos no interior de uma área geográfica; c) ela mesma determinada pela análise estatística da repartição dos traços; d) que possui uma continuidade espacial e temporal no interior da área; e) e apresentando por isso mesmo um caráter superindividual. [177]

Dizemos que esses gêneros de vida (por exemplo, na sociedade moderna, o hábito de fumar cigarros de papel, a ideologia democrática, o uso do colarinho, o sistema parlamentar, o jogo do rugby, os métodos de remoção dos detritos domésticos, a teoria da relatividade, o uso da eletricidade, etc.) apresentam - e por isso caracterizam sociedades humanas - um modo determinado de comportamento; a sociologia é o estudo desses modos de comportamento, porque a noção de sociedade se resolve, quando analisada, em uma simples palavra que utilizamos para designar um conjunto. Não se objete que essa definição conduz a sociologia à etnologia ${ }^{2}$, pois é evidentemente de uma divisão toda contingente do trabalho que provém a limitação dos trabalhos etnológicos às civilizações primitivas.

2 Hocart, A. Les progrès de l'homme. Paris: Payot, 1935. 
A observação inicial é a seguinte: só os métodos pacientes e modestos aplicados às sociedades primitivas pelos "trabalhadores sobre o terreno" fizeram, desde cinquenta anos, progredir nosso conhecimento das sociedades humanas. Quando tais métodos - e outros, sem dúvida, que ainda não percebemos - puderem ser aplicados, não só aos selvagens e povos desaparecidos, mas a todas as coletividades, inclusive à sociedade moderna, estaremos de posse de uma ciência na qual se fundirão etnologia e sociologia e que terá o nome de uma, da outra ou um terceiro, o que não importa. O papel da sociologia cultural, sintetizando os resultados já obtidos em seus respectivos domínios pela etnologia e pela sociologia tradicionais, é o de promover essa evolução.

Eis pelo quê não posso estar inteiramente de acordo com o senhor Fernando de Azevedo, quando escreve em seu belo livro:

Se, porém, incluirmos na definição de cultura não só as criações imateriais (costumes e instituições, etc.) como também as criações materiais do homem (móveis, utensílios, veículos e, em geral, os complexos dependentes de um dado material), estes estudos referentes aos dados materiais ou tecnológicos, de um alto interesse [178] antropológico e etnográfico, ultrapassam o domínio sociológico3 ${ }^{3}$

Com efeito, o que delimita uma ciência não é a natureza dos fatos que ela reserva para si. Falando estritamente, todas as ciências estudam os mesmos fenômenos. A usura de uma máquina é um fato físico, já que ela exprime a capacidade de resistência de um metal; químico, se um sal foi porventura introduzido na fundição; geográfico, na medida em que o fenômeno é explicável pelo clima; sociológico, finalmente, se decorrente da ação de um saboteur. Uma ciência não é, pois, definível pela categoria dos fatos que ela isola, mas pelo sistema de relações onde esses fatos são suscetíveis - ao mesmo título que muitos outros - de estarem implicados. Só esse sistema constitui por sua análise um objeto específico.

Ora, é conveniente notarmos que, do ponto de vista das relações específicas que são o objeto da sociologia, não há nenhuma diferença entre o comportamento social de um costume e o de um objeto. Quando um etnólogo estuda um produto

3 Azevedo, F. Princípios de sociologia. São Paulo: Nacional, 1935. p. 381. Apoiando sua concepção, o senhor F. de Azevedo cita a seguinte frase do senhor Bouglé: "O aspecto social da nutrição não está no facto de comer, nem no que se come, mas na maneira de comer". Mas onde encontrar um melhor exemplo de fato social que, para um dado povo, o fato de escolher tal alimento e excluir tal outro? 
material, por exemplo, o arco, procura a data e o local de seu nascimento, quais os fatores que explicam esse nascimento e sua localização no seio de um ciclo cultural dado, como finalmente o arco se expandia, onde penetrou, as modificações culturais que trouxe, etc. Mas, quando um sábio - qualquer que seja seu nome analisa uma instituição, digamos o totemismo, que poderia nele procurar senão precisamente esses mesmos caracteres para os quais a experiência revela um idêntico modo de comportamento?

Por mais paradoxal que pareça a afirmação, temos razão afirmando que o objeto da sociologia não é o social, mas o cultural. O social está compreendido no cultural, como uma de suas categorias. Não representa um conjunto de fenômenos específicos. Afirmando isso, não estamos em contradição com Durkheim, muito pelo contrário. Durkheim tinha perfeitamente apreendido a especificidade do estudo sociológico, mas não concebera ainda sua extensão. Quando afirma a especificidade das relações sociais, é relativamente às relações geográficas, psicológicas, etc. Apontamos [179] apenas a seguinte precisão a seu comentário: o caráter de especificidade não pertence ao fato social como tal, mas, na medida em que exprime um dos aspectos, é um dos “complexos" cujo conjunto constitui o domínio da cultura.

Substituindo a célebre fórmula das "Regras" - os fatos sociais não podem ser explicados senão por fatos sociais - por uma nova fórmula - omnis cultura ex cultura $^{4}$-, a sociologia cultural não trai o autor de "O Suicídio"; ela permanece na linha de sua inspiração ${ }^{5}$.

Os dois programas se correspondem; com efeito, um traço cultural, qualquer que seja ele, depende de leis que não se reencontram, nem no domínio da biologia nem no da psicologia, que aparecem no momento em que a noção de cultura está constituída e desaparecem com ela. E, quando tendo seguido o traço cultural em todos os seus deslocamentos e suas transformações, o sociólogo, conduzido à sua aparição inicial, dá a esta o nome de "mutação"6, o faz para exprimir, fora de toda a consideração metafísica, que, a partir do momento em que o traço cultural não é mais formulável em termos de cultura, escapa à sua análise para pertencer a outras disciplinas.

4 Lowie, R. Culture and ethnology. New York: Peter Smith, 1929. ch. IV, p. 66.

5 Sobre tal ponto, poderemos, sem dúvida, recorrer a um adversário encarniçado da sociologia cultural: "Foi Durkheim o primeiro a atribuir aos fatos culturais uma existência exterior e constrangedora. É pois seu ponto de vista que reaparece na concepção culturista do supra-individual, embora em termos modificados" (AвEL, T. Is a cultural sociology possible? The American Journal of Sociology, Mars 1930).

6 Montandon, G. Prefácio. In: Hocart, A. Les progrès de l’homme. Paris: Payot, 1935. 
Não há, pois, razão que afirme ser o caráter consciente um elemento indissociável do fato social7. Este - dizem - é essencialmente “cousa de alguém”. Uma lei que se não considera como "representada" reduz-se a uma série de traços pretos sobre branco. Um quadro definido, sem considerar sua natureza como espetáculo, é apenas uma marca de manchas coloradas. Mas um elemento consciente é indispensável a qualquer ciência, seja qual for. É a consciência do sábio que transforma em fato científico o que, por si só, não passa de um aglomerado de sensações. Responder-nos-ão, sem dúvida, que, em matéria de fatos sociais, a consciência não está [180] apenas no indivíduo que estuda, mas também no objeto estudado. Pretendemos, ao contrário, que uma análise científica não deve, em caso nenhum, considerar este último elemento. É porque considero um desenho africano como um puro conjunto de linhas e cortes que posso conhecer a cultura negra. Qualquer outra atitude conduziria a especulações perigosas sobre a alma do indígena ${ }^{8}$.

A essas razões gerais ajunta-se outra, tirada da consideração das exigências imediatas das pesquisas sociais. Conhecemos as instituições, os costumes das coletividades, como se desenvolveram durante um período de aproximadamente dez mil anos. Sua cultura material, no entanto, nos é parcialmente dada para uma duração que podemos avaliar bem maior que dez vezes tal tempo. Se nos transportarmos do tempo para o espaço, a relação é quase a mesma. A civilização material dos povos primitivos é conhecida em conjunto, mas a verdadeira significação das instituições sociais, sua materialidade, só agora começa a ser entrevista, o que é suficientemente demonstrado pelo completo revolucionamento de nossas concepções sobre as sociedades australianas. Restringir o sociológico ao social é, pois, reduzir a nada toda a possibilidade de generalização. O estudo do objeto revela um comportamento idêntico ao da instituição. Referindo-se, porém, a períodos históricos infinitamente mais longos, a espaços geográficos infinitamente mais vastos, permite perceber relações igualmente válidas no domínio dos costumes e das regras sociais, mas cujo estudo jamais teria bastado para desentranhar.

Não é tudo. Na medida em que Durkheim teve profunda razão, afirmando que os fatos sociais devem ser tratados "como coisas", é evidente que as coisas sociais realizam essa reivindicação de modo todo imediato, enquanto as repre-

7 ZnANIECKI, F. The object matter of sociology. The American Journal of Sociology, I-XXXII, jan. 1927.

8 Pretendeu-se, por vezes, assimilar ao behaviorismo a concepção que defendemos aqui; nada mais absurdo. A sociologia cultural é exatamente o contrário do behaviorismo. Este quis, à tort, banir a consciência do domínio que é seu por excelência: o da psicologia. A sociologia cultural pretende, ao contrário, impedir que se introduza a consciência em um domínio que lhe é totalmente estranho. 
sentações pedem um trabalho preliminar de redução. Tomemos um exemplo: se Durkheim realizou completamente o programa traçado em "As regras", foi bem em sua memória, contestável quanto à conclusão, mas metodologicamente [181] admirável, sobre Les origines de la prohibition de l'inceste ${ }^{9}$. O fim é reduzir a interdição moderna das relações consanguíneas à regra de exogamia em vigor nas sociedades totêmicas. Por que agora tal redução de uma regra jurídica a outra regra jurídica? Precisamente porque a proibição do incesto, impregnada de valorações morais e de reações tornadas instintivas, aparece-nos necessariamente com um caráter ideal. Reduzindo-a, pela análise crítica, a um fenômeno totêmico, retira-se dele a significação emotiva, moral, filosófica, e passa a existir como se não fosse atualmente pensada, conferindo-lhe caráter de coisa.

O trabalho sociológico, porém, só então começa, porque o fato da exogamia, sua relação com o totemismo, sua sobrevivência em nossa civilização devem ainda, pelo método cultural, ser reduzidos a elementos seja inteligíveis, seja irredutíveis. Toda a memória de Durkheim - quer ele tenha ou não percebido isso - é apenas um tratamento prévio do fenômeno social, destinado a lhe conferir esse caráter de coisa, que dá margem ao esforço intelectual. Ora, esse caráter, um machado ou um vaso o possuem de modo imediato. Não nos devemos, pois, admirar, se os resultados fundamentais aos quais chegamos no estudo das coletividades humanas são devidos à arqueologia e à etnologia e se a sociologia, sem o estudo dos objetos materiais e sem o conhecimento de seu comportamento (aplicável e aplicado, já se vê, ao conjunto dos fenômenos sociais), se acha praticamente paralisada.

Não esqueçamos, todavia, que esse conhecimento tira todo o seu valor de suas possibilidades de generalização. O objeto é apenas o sinal visível do grupo que o utiliza. Que admirável programa, para a sociologia cultural, tentar explicar o nascimento, o desenvolvimento, o itinerário de uma crença, religião, superstição, teoria científica! Ter-se-á já pensado no que poderia trazer em sugestões sociológicas a manifestação visível, no plano de uma cidade, no momento em que uma notícia é difundida pelo rádio, dos diferentes pontos onde é recebida como verdadeira ou falsa? Tais investigações deveriam, porém, para ter eficácia, ser conduzidas como se se tratasse não de uma representação, de uma crença, de uma atitude [182] mental, mas precisamente de um objeto desprovido de elemento consciente; como esse, manifestariam as mesmas relações objetivas, cujos reconhecimento, verificação e desenvolvimento são a base essencial de qualquer trabalho sociológico. Invenção, difusão, acúmulo e continuidade oferecem, para o estudo das instituições, como

9 Année Sociologique, $1^{\circ}$ ano, p. 1-70. 
para o dos objetos, as categorias fundamentais do comportamento das coisas sociais.

É sem dúvida supérfluo notar que essa atitude nada tem de comum com a posição habitualmente designada sob o nome de "materialismo histórico". Expresso nos termos da sociologia cultural, o determinismo econômico significa que o complexo técnico é, relativamente aos outros, um complexo dominante. Que essa afirmação seja ou não fundamentada, isso representa um ponto de vista no interior da sociologia cultural. Aceitemo-lo ou o rejeitemos, as razões pelas quais demos conta da importância dos elementos materiais na análise da cultura subsistem integralmente. Deveremos, por outro lado, lembrar que o verdadeiro fundador da sociologia cultural - quero dizer Friedrich Ratzel - dificilmente poderia ser tido como marxista e que o único filósofo a que se tenham abertamente ligado certos teóricos da cultura - o que, de nossa parte, não podemos aceitar - é o autor da Evolução Criadora?

Não é menos curioso se ver alguns adversários da sociologia cultural, como parte do marxismo, aliarem-se à uma parte do americanismo. Sem dúvida, o ponto de vista cultural conta, nos Estados Unidos, com ilustres defensores; aí também se encontram seus mais encarniçados adversários ${ }^{10}$. A lista, porém, dos teóricos europeus de cultura não é menos imponente. Rivers e Elliot Smith na Inglaterra; Ratzel, Graebner, Schmidt, Menghin, Frobenius, na Europa Central; e Montandon na França bastam para conferir ao movimento um valor universal. Podemos facilmente disso nos inteirar vendo até que ponto na luta contra a sociologia cultural recomeça a história: nem ao menos há o esforço de ajustar a esse novo uso os velhos argumentos que serviram no combate a [183] Durkheim: desconhecimento dos valores morais, acusação de materialismo, etc. Afirma-se novamente a irredutibilidade das ciências da natureza e das ciências do homem ${ }^{11}$; como anteriormente Tarde, invoca-se, contra a especificidade do fato cultural, a explicação pela psicologia ${ }^{12}$. É que, como antigamente Durkheim e seus colabora-

10 Para os primeiros, Wissler, Lowie, Goldenweiser, Kroeber; Allport e Abel para os segundos.

11 "Não pode haver nenhuma conexão lógica possível entre os juízos científicos... e aqueles de que são o objeto os fenômenos culturais. Há aí dois planos de investigação científica que nunca podem coincidir, mesmo parcialmente" (ZNANIECKI, op. cit., p. 537).

12 O psicólogo americano Floyd H. Allport denuncia o "erro de substituir o grupo como um todo como princípio de explicação, aos indivíduos no grupo" - "O que o sociólogo chama uma instituição é, do ponto de vista do psicólogo, simplesmente as modalidades semelhantes e recíprocas da conduta individual, retinidas aos utensílios que o indivíduo fabricou para manifestá-las" (citado por Willey, M. The validity of the culture concept. The American Journal of Sociology, September 1929). 
dores das "Année" faziam, a sociologia cultural luta hoje pelo estabelecimento de uma sociologia positiva: a sociologia será cultural ou não existirá.

A sociologia cultural possui na América do Sul títulos particulares. Foi ao Brasil, ao Paraguai, à Bolívia que Nordenskiöld pediu os elementos de seus admiráveis Comparative ethnographical studies, perfeita ilustração do método cultural.

Força é, pois, reconhecer que o ensino da sociologia na Faculdade de Filosofia, Ciências e Letras não está exatamente adaptado às exigências de nosso ponto de vista. Os programas exigiriam séria revisão. Particularmente contestável parece ser o agrupamento de matérias exigidas para os exames de fim de ano.

A importância dos conhecimentos filosóficos para os estudantes de sociologia não pode ser posta em dúvida. Conviria, porém, precisá-los para o fim a que se destinam: a história da filosofia deve ter por função desembaraçar o programa propriamente sociológico do estudo, anacrônico em tal lugar, da filosofia social. O ensino psicológico deveria estar inteiramente "centrado" em torno do problema, fundamental para a sociologia cultural, de saber em que medida a cultura exprime estruturas mentais inatas do homem, em que medida [184] ela é adquirida e quais são os processos neuropsíquicos dessa aquisição; enfim, a lógica, ausente atualmente do programa, permitiria aos estudantes conceberem a importância da evolução metodológica atual da sociologia.

O erro essencial dos programas reside na ausência aproximadamente completa de elos entre ensino sociológico e geográfico, de um lado, sociológico e etnográfico de outro. Um curso facultativo de geografia humana está previsto, é verdade, para os estudantes de sociologia, mas a geografia geral não lhes é menos indispensável. O desenvolvimento crescente de pontos de vista ecológico e cultural impõe à sociologia métodos de trabalho - estatísticas de repartição espacial, estabelecimento e interpretações de mapas culturais, etc. - que pertencem, antes de tudo, à geografia. Só uma boa formação geográfica poderia assegurar-lhes solidamente a prática.

Devemos, enfim, considerar como necessária a obrigação para nossos estudantes de seguirem os cursos de etnografia. Relativamente à sociologia cultural, esforço de sistematização racional, a etnografia, ciência puramente descritiva, conserva evidentemente sua independência. Mas quem não vê a intimidade dos elos que as unem? Não nos cabe dizer se um estudante de etnografia deve ser um sociólogo, mas é fora de dúvida que um sociólogo deve, em primeiro lugar, possuir boa formação etnográfica, já que a existência da sociologia cultural, inteiramente nascida “sobre o terreno", é, antes de mais nada, a confirmação esmagadora destas 
palavras de Durkheim: "A etnografia muitas vezes determina, nos diferentes ramos da sociologia, as mais fecundas revoluções"13.

13 "As formas elementares da vida religiosa" (p. 9). 
